\title{
IMPLEMENTASI KEBIJAKAN PENGELOLAAN SAMPAH DI KABUPATEN BENGKULU SELATAN
}

\author{
Bella Dwi Hastuti', Faizal Anwar'2, Titi Darmi ${ }^{*}$
}

\begin{abstract}
1,2,3 Program Studi Administrasi Publik, Fakultas IImu Sosial dan IImu Politik, Universitas Muhammadiyah Bengkulu Bengkulu, Indonesia titi.harmadi@gmail.com
\end{abstract}

Submitted: 15 September 202

Revised: 1 December 202

Accepted: 5 December 2021

\begin{abstract}
The purpose of this study was to determine the implementation of waste management policies and to find out the inhibiting factors in the implementation of waste management policies in South Bengkulu Regency. This study used descriptive qualitative method. The informants were determined by purposive sampling technique. Data were collected by means of observation, interviews, and documentation. Meanwhile, data analysis used the interactive model of Miles and Huberman. The results of this study indicated that the Implementation of Local Government Regulation No. o1 of 2017 concerning Waste Management in South Bengkulu Regency has been running according to the standards and procedures that have been set, but in its implementation, it has not been fully materialized in accordance with the contents of the policy, and there still discrepancies obtained from the results of the implementation of the policy. Some of the factors that become obstacles in implementing waste management policies were first, communication: lack of budget for conducting outreach. Second, Resources: limited human resources who were experts in the field of solid waste, lack of good facilities, TPS, $3 R$ TPS as well as a lack of waste transporting fleets and limited budget costs. Third, Disposition: there were still officials who carried out their main tasks and functions outside the existing regulations. Fourth, the structure of the bureaucracy: there were officers/ staff who still carried out the main tasks and functions that were not in accordance with the established SOP.
\end{abstract}

Keywords: public policy; policy implementation; waste management

\begin{abstract}
ABSTRAK
PTujuan studi ini adalah untuk mengetahui Implementasi Kebijakan Pengelolaan Sampah dan mengetahui faktor penghambat dalam Implementasi Kebijakan Pengelolaan Sampah di Kabupaten Bengkulu Selatan. Studi ini menggunakan metode deskripsi kualitatif. Informan penelitian ditetapkan dengan teknik purposive sampling. Data dikumpulkan dengan cara observasi, wawancara, dan dokumentasi. Sedangkan analisis data menggunakan model interaktif dari Miles and $\mathrm{Hu}-$ berman. Hasil dari studi ini menunjukkan bahwa Implementasi Kebijakan Perda No. O1 Tahun 2017 Tentang Pengelolaan Sampah di Kabupaten Bengkulu Selatan sudah berjalan sesuai standar dan prosedur yang telah ditetapkan namun dalam pelaksanaannya belum sepenuhnya terealisasi sesuai dengan isi kebijakan, serta masih ada ketidaksesuaian yang didapat dari hasil pelaksanaan kebijakan. Adapun beberapa faktor yang menjadi penghambat dalam implementasi kebijakan pengelolaan sampah adalah: pertama, Komunikasi: kurangnya anggaran biaya untuk melakukan sosialisasi. Kedua, Sumber Daya: terbatasnya SDM yang ahli di bidang persampahan, kurangnya fasilitas baik, TPS, TPS $3 R$ serta kurangnya armada pengangkut sampah dan terbatasnya anggaran biaya. Ketiga, Disposisi: masih ada aparat yang melaksanakan tupoksi di luar peraturan yang ada. Keempat, Struktur Birokrasi: masih petugas/pelaksana yang menjalankan tupoksi tidak sesuai dengan SOP yang telah ditetapkan.
\end{abstract}

Kata Kunci: kebijakan publik; implementasi kebijakan; pengelolaan sampah 


\section{PENDAHULUAN}

Hampir diseluruh negara yang ada di dunia memiliki permasalahan tersendiri di dalam negaranya masing-masing, permasalahannya juga beragam misalnya permasalahan ekonomi, permasalahan kependudukan, permasalahan sosial, budaya serta permasalahan lingkungan. Di Indonesia permasalahan lingkungan masih menjadi permasalahan pokok. Salah satu permasalahan lingkungan yang hingga saat ini masih menjadi permasalahan adalah permasalahan sampah. Permasalahan sampah masih menjadi sorotan dan hampir yang terjadi di semua kota di Indonesia mengalami kendala dalam pengelolaan sampah. Khususnya di perkotaan, mengelola sampah di perkotaan dapat dikatakan terbilang sulit dan memiliki banyak tantangan dalam pengelolaannya. Semakin luasnya wilayah perkotaan di suatu wilayah maka akan menghasilkan lebih banyak sampah yang dihasilkan, sehingga pengelolaanya lebih sukar (Fernando, 2019)most of them have not been successful. Thus, the main purpose of this study is to examine major factors affecting successful policy implementation of the SWM. Further, the study identifies problems and challenges faced in the implementation of SWM. Both qualitative and quantitative methods were used to gather primary and secondary data. Interview and in-depth discussions were conducted with selected officers who are responsible for implementation of SWM system to identify problems and challenges at the implementation level. Among the 48 LGs in the Western Province, 50\% (twenty-four

Pengelolaan sampah disini merupakan tanggung jawab pemerintah yang berbentuk sebuah pelayanan, yakni dengan caraamembuat kebijakan mengenai pengelolaan sampah(Fitri, Ati, \& Suyeno, 2019). Adanya kebijakan tentang pengelolaan sampah belum menentukan pengelolaan sampah bisa dikelola dengan baik. Dimana tidak jarang kita temukan bahwa instansi yang memiliki tugas dalam penanganan sampah kurang mampu mengatasi persoalan sampah, sehingga menyebabkan pengelolaan sampah yang tidak efektif dan dapat memberikan dampak negatif bagi kesehatan maupunllingkungan (Wichai-utcha \& Chavalparit, 2019)such as packaging, agriculture, automobile parts, electronic applications and medical devices. The plastic fabrication process can be modified to form various shapes, colors and specifications according to customer needs. Consequently, the amount of plastic waste is increasing due to the increase in plastic consumption because of the increasing population. Moreover, the problem of marine plastic debris is on the rise globally, including in Thailand, which results from the irresponsibility of mankind. Generally, plastic waste in Thailand can be generated from industrial processes and households. These two waste sources have caused the rise in plastic waste, which has contributed to the problem of waste management in Thailand. Additionally, Thailand is one of the contributors to the leakage of plastic waste into the ocean, which results from inefficient waste management. To reduce the impacts of plastic waste, effective measures have to be applied, such as reducing, reusing and recycling (3Rs

Salah satu kabupaten yang memiliki kendala dalam pengelolaan sampah adalah Kabupaten Bengkulu Selatan. Kab. Bengkulu Selatan merupakan Kabupaten dari 10 Kabupaten yang berada di ProvinsiiBengkulu. Luas wilayah mencapai kurang lebih 11.8.610 Ha. terbagi atas 11 kecamatan. Pertumbuhan penduduk yang terus mengalami peningkatan setiap tahunnya sehingga menyebabkan dampak pada pengelolaan sampah(Mengoptimalisasi \& Sampah, 2021). Pertumbuhan penduduk yang terus mengalami peningkatan dan sehingga menyebabakan volume sampah yang dihasilkan di Kabupaten Bengkulu terus mengalami peningkatan tercatat pada tahun 2018 sampah yang dihasilkan mencapai 4.341.148 ton sedangkan 2019 jumlah sampah yang dihasilkan meningkat menjadi 5.328.00o ton (Lu \& Sidortsov, 2019).

Pemerintahan Bengkulu Selatan telah mengeluarkan kebijakan berupa peraturan daerah sebagai tanda keseriusan-nya dalam mengatasi permasalah sampah di Bengkulu Selatan. Adapun tujuan dari peraturan daerah ini yakni mewujudkan Kabupaten Bengkulu Selatan yang bersih dari permasalahan sampah demi menunjang kelestarian lingkungan hidup dan meningkatkan kesehatan masyarakat, kualitas lingkungan serta menjadikan sampah sebagai sumber daya. Peraturan daerah ini baru terselenggara di Bengkulu Selatan kurang lebih 3 tahun setelah ditetapkan pada tanggal 25 januari 2017.

Berdasarkan hasil pencarian literatur awal yang telah dilakukan peneliti(Danang Aji Kurniawan \& Ahmad Zaenal Santoso, 2021), Imple- 
J1AD: Jurnal Ilmu Administrasi dan Pemerintahan Indonesia Volume 02 No 02 December 2021

Pages 92-101

mentasi kebijakan pengelolaan sampah di Kabupaten Bengkulu Selatan belum terkelola dengan baik. Jika dilihat pada saat ini pengelolaan sampah yang dilakukan di Kabupaten Bengkulu Selatan masih sebatas rutinitas saja, sehingga dalam pelaksanaanya belum optimal. Pengelolaan sampah di Kabupaten Bengkulu Selatan masih diangkut langsung dari rumah ke rumah atau dari tempat kontainer tempat sampah sementara oleh petugas dengan menggunakan kendaraan kemudian langsung diangkut Ke Tempat Pemrosesan Akhir (TPA). Serta masih terdapat penumpukan sampah dibebeberapa lokasi di Kabupaten Bengkulu Selatan dan masih minimnya partisipasi masyarakat atau masih kurangnya kesadaran masyarakat dalam membuang sampah pada tempatnya (Sharma et al., 2020).

Menurut Lu \& Sidortsov, (2019)menyatakan bahwa suatu kebijakan merupakan rangkaian atau tindakan yang ditetapkan oleh pemerinth untuk tujuan tetentu dalam memecahkan masalah-masalah publik yang sedang berkembang di lingkungan masyarakat yang membutuhkan tindakan penyelesaian. Adanya Kebijakan yang telah ditetapkan dapat diharapakan akan mampu mengatasi dan memberikan suatu manfaat atau memberikan suatu harapan pada suatu kondisi yang memiliki dampak bagi masyarakat atau banyak pihak(Rulinawaty Kasmad, Samboteng, \& Mahsyar, 2019). akan tetapi, adanya kebijakan yang telah ditetapakan tidak serta-merta mampu menyelsaikan masalah yang menjadi acuhan dalam perumusan kebijakan tersebut(Alwi \& Kasmad, 2018)their commitment to the program of Gernas Kakao (Cocoa National Movement, dan suatu kebijakan tidak hanya dirumuskan, dibuat dan ditetapkan, serta tidak diimplementasikan, sebuah kebijakan itu harus diimplementasikan agar bisa mencapai tujuan yang telah ditetapkan (Zorpas, 2020).

Menurut implementasi kebijakan dalam berbagai model implementasi(Sabatier \& Mazmania, 1980) menyatakan implementasi kebijakan sering dianggap sebagai suatu pelaksanaan dari apa yang telah ditetapakan oleh pemerintah dan seolah-olah tahapiimplementasi ini tidak berpengaruh terhadap keberhasilan suatu kebijkan. Akan tetapi kenyataannya tahap implementasi sangat menentukan keberhasilan suatu kebijkan karena suatu kebijakan tidak akan berarti dan tidak dapat mencapai sutu tujuan yang telah ditetapkan jika tidak di implmentasikan dengan baik dan benar.(Van Meter \& Van Horn, 1975) Adapun empat variabel menurut Edward III yang berperan penting dalam mencapai keberhasilan implementasi kebijakan ialah meliputi : Komunikasi, Sumber daya, Disposisi, dan Struktur Birokrasi. Dengan demikian, implementasi kebijakan pengelolaan sampah di Kabupaten Bengkulu Selatan sudah terealisasi dengan baik jika kebijakan tersebut telah di komunikasikan, telah memiliki sumber daya memadai dan memiliki fasilitas dan pembiyaan yang cukup, adanya keinginan para pelaksana dalam melakukan kebijakan serta melaksanaan tupoksi dan menerapkan SOP yang telah ditetapkan.

Belum terkelolahnya pengelolaan sampah di Kabupaten Bengkulu Selatan secara optimal, bisa dikatakan sebagai salah satu tanda bahwa implementasi kebijakan pengolaan sampah yang diterapakan di Kabupaten Bengkulu Selatan masih mengalami kendala dan hamabtan dalam pelaksanaannya, maka dari itu tujuan dari penelitian ini yakni mengetahui bagaimana Implementasi Kebijakan Pengelolaan Sampah dan untuk mengetahui apa saja faktor yang menghambat Implementasi Kebijkan Pengelolaan Sampah di Kabupaten Bengkulu Selatan.

\section{METODE PENELITIAN}

Penelitian ini dilakukan di DLHK di Kabupaten Bengkulu Selatan dan TPA Padang Gilang/TPA Kayu Agau Manna dan tempat terkait penelitian. Sedangkan penelitian dilakukanmulai tanggal 17 Desember - 30 Desember 2020.

Adapun Pendekatan dalam penelitian ini yakni pendekatan kualitatif yang bersifat deskriptif (Yin, Rk, 2013)but iterative process." This statement is supported by a visual which is displayed on the first page of each chapter. Each chapter contains one step in the linear process of case design (planning, designing, preparing, collecting, analyzing, and sharing. Dimana penelitian ini bertujuan untuk mengungkapkan fakta serta yang terjadi di lapangan pada saat penelitian berlangsung. di sini peneliti berupaya untuk mengungkapkan fakta ataupun kejadian berupaamasalah mengenai implementasi kebijakan tentang Pengelolaan Sampah di Kab. Bengkulu Selatan.

Sumber data penelitian yang digunakan terdiri dari dua yaitu sumber data primer dan sumber data sekunder. Sumber data primer diperoleh atau dikumpulkan berdasarkan hasil 
wawancara dengan informan yang terkait dan data hasil pengamatan langsung yang dilakukan peneliti.Sumber data sekunder diperoleh dari sumber tertulis seperti, dari data arsip, dokumen pribadi dan dokumen resmi yang ada di DLHK Bengkulu Selatan yang terkait penelitian.

Fokus dalam penelitian ini ialah pada implementasi kebijakan pengelolaan sampah di Kabupaten Bengkulu Selatan dengan mengkaji dari beberapa variabel yang mempengaruhi proses implementasi kebijakan berdasarkan teori George C. Edward III yang meliputi Komunikasi, Sumberrdaya, Disposisi, Struktur Birokrasi.

1.Komunikasi : mengetahui bagaimana kebijakan perda No. 01 Tahun 2017 Tentang Pengelolaan Sampah di Kabupaten Bengkulu Selatan dikomunikasikan, peneliti membahas 3 indikator yaitu transmisi, kejelasan, dan konsistensi

2. Sumber Daya : mengetahui bagaimana sumber daya dalam mengimplementasi kebijakan Pengelolaan Sampah di Kab. Bengkulu Selatan. Peneliti membahas 3 indikator dari sumber daya, yaitu staf, fasilitas, dan pembiayaan.

3. Disposisi : mengetahui bagaimana disposisi/sikap pelaksana dalam mengimplementasi kebijakan Pengelolaan Sampah di Kabupaten Bengkulu Selatan. Peneliti menganalisis dari 2 indikator yaitu tingkat kepatuhan pelaksana dan insentif

4. Struktur Birokrasi : mengetahui bagaimana struktur Birokrasi dalam mengimplementasikan kebijakan perda tentang pengelolaan sampah di kabupaten Bengkulu Selatan. Peneliti menganalisis dari 2 indikator yaitu Standar oprating prosedure (SOP) dan Penyebarn tanggung jawab.

\section{Informan Penelitian}

Informan penelitian ditetapkan dengan teknik purposive samplin, dimana informan yang dipilih berdasarkan pertimbangan tertentu. Adapun informan yang dipilih berdasarkan pertimbanagan dalam penelitian ini adalah pejabat yang berwenang dan orang-orang yang terkait langsung dalam pelaksanaan kebijakan pengelolaan sampah. Berdasarkan pertimbangan tersebut maka informan dalam penelitian ini adalah 7 informan yang meliputi Kepala DLHK, Kabid. Kebrsihan DLHK, Seksi pengelo- laansampah dan limbah B3, Pelaksana di Bidang PengelolaanSampah dan Limbah B3, Petugas TPA dan petugas pengangkut sampah dan masyarakat.

\section{Teknik Pengumpulan Data}

Teknik pengupulan data disini ada 3 tahap yaitu:

1. Observasi

Dalam penelitian ini peneliti melakukanpengamatan terhadap objek di tempat penelitian secara langsung untuk melihat keadaan sesuai dengan situasi yang ada di lapangan yaitu melihat kondisi sebenarnya diIapangan. Observasi ini bertujuan agar mempermuda peneliti dalam melakukan tahapan selanjutnya yaitu wawancara mendalam terkait penelitian.

2. Wawancara

peneliti menggunakan wawancara secara mendalam serta terstruktur dengan informan penelitian demi mendapatkan penjelasan yang rinci dan mendalam mengenai implementasi kebijakan pengelolaan sampah di Kabupaten Bengkulu Selatan.

3. Dokumentasi

Data melalui dokumentasi dikumpulkan dari dokumen-dokumen yang berasal dari kantor DLHK Kab. Bengkulu Selatan.

\section{Teknik Analisis Data}

Analisis data dalam penelitian ini menggunakan analisis data di lapangan model Miles and Huberman dalam (César et al., 2017) yaitu:

1. Data Reduction (Reduksi Data)

Peneliti melakukan reduksi data secara bertahap yaitu dengan cara membuat ringkasan dari data yang telah dipilih dan diolahdari semuah data yang didapat melalui hasil wawancara, pengamatan,ddokumen atau arsip yang kemudian dirangkum intinya.

2. Data Display (Penyajian data)

Di tahap ini peneliti menyusun data yang telah dirangkum dalam bentuk uraian singkat kemudian menjadi pembahasan mengenai implmentasi kebijakan pengelolaan sampah di Kabupaten Bengkulu Selatan.

3 Conclusion Drawing/verification (penarikan kesimpulan/verifikasi) 
J1AD: Jurnal Ilmu Administrasi dan Pemerintahan Indonesia Volume 02 No 02 December 2021 Pages 92-101

Tahapan ini ialah tahap penarikan kesimpulan yang disimpulkan berdasarkan reduksi data dan penyajian dan penyajian data yang telah dilakukan sebelumnya(Robert K.Yin, n.d.).

\section{HASIL DAN PEMBAHASAN}

\section{Temuan-temuan umum dalam penelitian}

DLHK dalam menjalankan tugas pelayanan persampahan di Kabupaten Bengkulu Se- latan, dipimpin oleh seorang kepala dinas dan didukung oleh 6 bidang sekretariat dalam melaksanakan kegiatan pelayanan di Kab. Bengkulu Selatan.

Pelayanan persampah yang dilaksanakan baru menjangkau 3 kecamatan dari 11 kecamatan yang ada, belum semua kecamatan terlayani pelayanan persampahan di Kabupeten Bengkulu dikarenakan masih terbatasnya anggaran dan fasilitas yang dimiliki dalam pelaksanaan pengelolaan sampah.

Tabel 1. Data pegawai PNS di DLHK berdasarkan pendidikan dan jeniskelamin.

\begin{tabular}{|c|c|c|c|c|c|}
\hline \multirow{2}{*}{ No. } & \multirow{2}{*}{ Pendidikan } & \multicolumn{2}{|c|}{ Jenis Kelamin } & \multirow{2}{*}{ Jumlah } & \multirow{2}{*}{$\begin{array}{c}\text { Persentase } \\
\text { (\%) }\end{array}$} \\
\hline & & Laki-Laki & Perempuan & & \\
\hline 1 & $\mathrm{SD} / \mathrm{SR}$ & - & 1 & 1 & $2 \%$ \\
\hline 2 & SLTP/ST & - & - & - & - \\
\hline 3 & SLTA & 5 & 7 & 12 & $22 \%$ \\
\hline 4 & D.I & - & - & - & - \\
\hline 5 & D.II & - & - & - & - \\
\hline 6 & D.III & - & 1 & 1 & $2 \%$ \\
\hline 7 & D.IV & - & - & - & - \\
\hline 8 & S.1 & 15 & 18 & 33 & $60 \%$ \\
\hline 9 & S.2 & 4 & 4 & 8 & $14 \%$ \\
\hline 10 & S.3 & - & - & - & - \\
\hline & Jumlah & 24 & 31 & 55 & $100 \%$ \\
\hline
\end{tabular}

Berdasarkan Tabel 1 di atas dapat diketahui bahwa jika dilihat dari tingkat pendidikan pegawai di DLHK paling banyak berada di tingkat S.1. yaitu dengan jumlah 33 pegawai. Jadi apabila dilihat dari tingkat pendidikan pegawai/ sumber daya manusia di DLHK sudah dapat dikatakan baik, hal ini dilihat dari mayoritas pegawai yang ada berpendidikan S1 dan bahkan ada 8 orang yang berpendidikan S2, dan hanya sebagian dari pegawai yang tingkat pendidikannya SD dan SLTA. Sedangkan untuk Jumlah petugas Lapangan dan petugas TPA yang telah ditetapkan dalam pelaksanaan kebijakan pengelolaan sampah di Kabupaten Bengkulu Selatan dapat dilihat pada Tabel 2.

Berdasarkan data di atas dapat disimpulkan bawah sumber daya manusia yang menjadi tenaga/petugas lapangan seperti pengangkut sampah sudah dikatakan cukup. Namun kalau untuk petugas kebersihan penyapu jalan itu sudah terlalu banyak.
Tabel 2. Jumlah petugas Lapangan dan petugas TPA

\begin{tabular}{lll}
\hline No & \multicolumn{1}{c}{ Petugas Lapangan } & $\begin{array}{l}\text { Jumlah } \\
\text { Petugas }\end{array}$ \\
\hline 1. & $\begin{array}{l}\text { Petugas Sopir Truck sam- } \\
\text { pah. Armoll, Buldoser dan }\end{array}$ & 13 Orang \\
& $\begin{array}{l}\text { Excavator. } \\
\text { 2. }\end{array}$ \\
& $\begin{array}{l}\text { Petugas pengangkut sam- } \\
\text { pah }\end{array}$ & 28 Orang \\
3. & $\begin{array}{l}\text { Petugas kebersihan pe- } \\
\text { nyapu jalan dan bibir pantai }\end{array}$ & \\
4. & Petugas TPA & 13 Orang \\
\hline
\end{tabular}

\section{Tempat Pemrosesan Akhir (TPA)}

Adapun grafik tahunan volume sampah di TPA Kayu Aghau tahun 2018, 2019 dan 2020 adalah digambarkan pada Gambar 1. 
5.328 .000

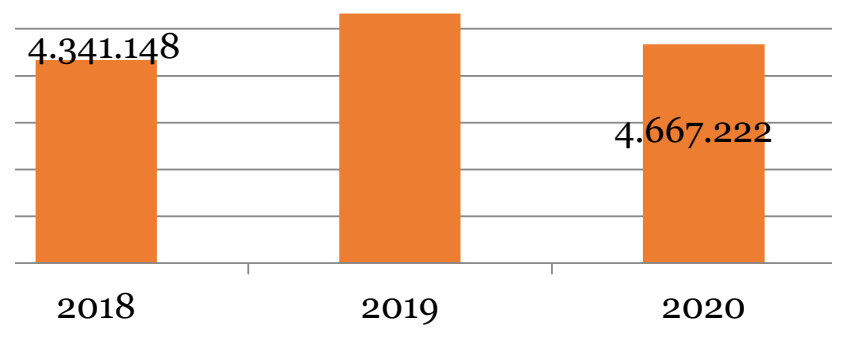

Gambar 1. Grafik Tahunan Volume Sampah Tahun 2018, 2019 dan 2020

Sumber : Dukumen Laporan tahunan diTPA Kayu Aghau Manna.

Berdasarkan grafik tahunan volume sampah di TPA Kayu Aghau tahun 2018, 2019, dan 2020. Terlihat di tahun 2018 sampai tahun 2019 mengalami kenaikan volume sampah yang dihasilkan di tahun 2018 berjumlah 4.341.148 dan mengalami kenaikan pada tahun 2019 adapun jumlah sampah yang dihasilkan di tahun 2019 adalah 5.328.00o sedangkan di tahun 2020 volume sampah mengalami penurunan dimana volume sampah yang dihasilkan di tahun 2020 berjumlah 4.667.222.

\section{Jumlah fasilitas}

Berdasarkan data yang telah ditemukan adapun jumlah fasilitas dalam pengeloaan sampah di Kab. Bengkulu Selatan dapat dilihat pada Tabel 3.

Tabel 3. Fasilitas pengelolaan sampah di Kab. Bengkulu Selatan

\begin{tabular}{llr}
\hline No. & Nama Fasilitas & Jumlah \\
\hline 1. & Truck Sampah & 6 Buah \\
2. & L3Oo & 1 Buah \\
3. & Armroll & 2 Buah \\
4. & Excavator & 1 Buah \\
5. & Buldoser & 1 Buah \\
6. & TPS Kontainer & 5 Buah \\
7. & TPS 3 R & 1 Buah \\
\hline
\end{tabular}

Sumber : Dokumen DLHK di Kabupaten Bengkulu Selatan.

Berdasarkan data di atas dapat dapat dikatakan bahwa fasilitas yang ada di Kabupaten BengkuluSelatan terdiri dari 6 buah Truck Sampah, 1 Buah L3oo dan 2 buah Armroll dan ada 2 alat berat yang disediakan di TPA yaitu 1 buah
Excavator dan 1 buah Buldoser. Sedangkan untuk TPS di setiap sudut Kota diletakkan 5 Buah Kontainer sampah dan memiliki 1 TPS $3 \mathrm{R}$.

Berdasaran rumusan masalah yang telah dirumuskan untuk mengetahui bagaimana implementasi kebijkan pengelolaaan sampah dan apa saja yang menjadi faktor penghamabat dalam pengelolaan sampah di kabupaten Bengkulu Selatan. peneliti menggunakan teori kebijkan yang di kemukakan oleh George Edwards III yang meliputi emapat variabel yaitu Komunikasi, Sumber Daya, Disposisi, dan Struktur Birokrasi.

\section{Komunikasi}

Berdasarakan hasil wawancara yang telah dilakukan, peneliti memeperoleh informasi bahwa penyampaian informasi/pesan mengenai kebijakan pengelolaan sampah di Kabupaten Bengkulu Selatan sudah dilaksanakan namun belum optimal, memang untuk penyampaian kebijakan dari DLHK kepada para staf/aparatur pelaksana kebijakan dan petugas lapangan telah disampaikan dengan baik. Namun untuk penyampaian kepada masyarakat masih kurang. hal ini disebabkan kurangnya anggaran biaya untuk menyelenggarakan sosialisasi, maka dari ini beluma ada penyelenggaraan sosialisasi secara langsung dari DLHK kepada masyarakat,. dalam hal ini DLHK hanya melakukan sosialisasi dengan cara ikut serta dalam suatu acara atau kegiatan misalnya kegiatan di kecamatan. Sedangkan untuk penyampaian tugas dan perintah yang telah diberikan sudah jelas dan konsistensi informasi/pesan yang diberikan tidak ada yang bertentangan atau tumpang tindih.

Menurut Edward III dalam Syahruddin (2018:58) menyatakan bahwa komunikasi sangat menentukan keberhasilan pencapaian tujuan dari implementasi kebijakan. Implementasi yang efektif baru akan tercapai apabila para pembuat keputusan sudah mengetahui apa yang akan mereka kerjakan. Begitu juga dalam Implementasi kebijakan Pengelolaan Sampah di Kab. Bengkulu Selatan akan tercapai apabila kebijakan dan tujuan dari kebijakan dikomunikasikan dengan baik kepada para pelaksan kebijakan. Sesuai dengan hasil penelitian berkaitan dengan komunikasi. Dapat diketahui bahwa komunikasi merupakan faktor yang sangat menentukan dari tercapainya tujuan dari implementasi kebijakan Pengelolaan sampah di Kabupaten Bengkulu Selatan. Melalui proses komunikasi staf, Petugas 
J1AD: Jurnal Ilmu Administrasi dan Pemerintahan Indonesia Volume 02 No 02 December 2021

Pages 92-101

lapangan serta masyarakat dapat berinteraksi, dan dengan adanya komunikasi DLHK selaku sebagai OPD yang mengurus masalah sampah di Kabupaten Bengkulu Selatan dapat memberikan informasi kepada masyarakat dalam mewujudkan kebijakan yang telah ditetapkan dalam menangani permasalahan sampah yang ada di Kabupaten Bengkulu Selatan

Berdasarkan hasil penelitian dapat dikatakan bahwa komunikasi yang dilaksanakan dalam Implmentasi Kebijakan Pengelolaan Sampah di Kabupaten Bengkulu Selatan telah terlaksana namun belum optimal. Memang komunikasi yang diberikan oleh para staf pelaksana dan petugas lapangan sudah dikomunikasikan baik, ini terbukti dari hasil penelitian bahwa para staf pelaksana kebijakan dan petugas lapangan sudah memahami apa yang diperintahkan dan apa yang harus dikerjakan, sedangkan untuk konsisten perintah yang diberikan oleh DLHK juga sudah konsisten tidak ada yang bertentangan dan tumpang tindih. Akan tetapi untuk sosialisasi yang disampaikan pihak DLHK agar masyarakat paham dan mengetahui dari isi dan tujuan dari kebijakan belum tersampaikan secara optimal. Belum optimalnya sosialisasi yang diberikan karena belum adanya pengadaan sosialisasi secara langsung oleh pihak DLHK kepada masyarakat karena tidak adanya anggaran untuk melakukan sosialisasi.

Pihak DLHK memang telah mengupayakan semaksimal mungkin agar sosialisasi tentang kebijakan pengelolaan sampah bisa sampai kepada masyarakat untuk mengatasi masalah tidak adanya anggaran untuk menyelenggarakan sosialisasi secara langsung, DLHK mensosialisasikan dengan lewat ikut serta dalam suatu kegiatan lain, misalnya kegiatan yang diadakan di kecamatan, biasanya mereka diberikan kesempatan atau meminta kesempatan untuk menyampaikan sosialisasi mengenai kebijakan pengelolaan sampah di Kabupaten Bengkulu Selatan di dalam kegiatan tersebut. Selain itu salah satu cara yang dilakukan pihak DLHK agar mempermudah masyarakat untuk mengetahui isi dan tujuan dari kebijkan yang telah ditetapkan adalah dengan mengguggah perda tersebut lewat media seperti media Internet.

\section{Sumber Daya}

Berdasarakan hasil wawancara yang telah dilakukan, peneliti memeperoleh informasi bahwa untuk jumlah dan tingkatan pendidikan sumberrdaya manusia seperti staf/ aparatur yang ada di DLHK sudah memadai. Namun untuk SDM yang mempunyai kemampuan di bidangpersampahan masih terbatas dan untuk tenaga lapangan atau pelaksana lapangan seperti petugas pengangkut sudah dikatakan cukup jika menimbang jumlah armada yang di punya. Sedangkan hasil dari penelitian terhadap fasilitas pendukung dan anggaran biaya dalam pelaksanaan kebijakan Sampah, masih memiliki anggaran dana oprasional yang terbatas dalam pelaksanaan pengelolaan sampah serta masih kekurangan fasilitas baik armada pengangkutan sampah, TPS dan TPS $3 \mathrm{R}$.

Sumberdaya yang dilihat dalam penelitian ini yaitu sdm dan sumber daya finansial. Sumber daya manusia yang dimaksud disini yaitu staf dan petugas lapangan seperti pengangkut sampah dan penyapu jalan. Sedangkan sumber daya finansial disini meliputi fasilitas dan pembiayaan dalam pelaksanaan kebijakan pengelolaansampah di Kabupaten BengkuluSelatan.

Berdasarkan hasil penelitian dapat diketahui bahwa SDM/staf yang ada di DLHK sudah cukup memadai, walupun masih terbatasnya $\mathrm{SDM} /$ staf yang ahli di bidang persampahan. Sedangkan petugas lapangan seperti tenaga pengangkut sampah sudah dapat dikatakan cukup jika diukur dengan jumlah armada pengangkut sampah, akan tetapi untuk petugas penyapu jalan dapat dikatakan sudah berlebihan untuk saat ini.

Selanjutnya sumber daya yang dilihat dalam penelitian ini adalah sumber daya finansial yang meliputi fasilitas dan pembiayaan. Sumber daya finansial terkait dengan fasilitas dalam implementasi kebijakan pengelolaan sampah di Kabupaten Bengkulu Selatan masih sangat kurang, baik dari fasilitas armada pengangkut sampah, TPS sementara, dan TPS $3 \mathrm{R}$. Fasilitas seperti armada pengangkut sampah yang ada di Kabupaten Bengkulu Selatan masih sangat minim, armada yang di kerahan dalam pengangkutan sampah cuma berjumlah 9 armada, begitu juga TPS, TPS yang ada di Kabupaten Bengkulu Selatan cuma ada 5 TPS.

Berdasarkan hasil wawancara dan pengamatan, 5 TPS ini belum mencukupi untuk menampung semua sampah dari masyarakat, hal ini terbukti dari fakta dilapangan di setiap TPS yang ada di Kabupaten Bengkulu Selatan belum 
bisa menampung semua Sampah yang ada. Hal ini menyebabkan masyarakat banyak membuang sampah di luar TPS sehingga sampah berceceran di luar TPS. Begitu juga berkaitan dengan sumber daya finansial kedua yaitu Pembiayaan, berdasarkan hasil penelitian dapat diketahui bahwa pembiayaan/anggaran biaya yang dimiliki DLHK dalam menyelenggarakan kebijakan pengelolaan sampah di Kabupaten Bengkulu Selatan masih sangat terbatas.

Kondisi pembiayaan oprasional dalam pengelolaan sampah yang masih terbatas dan minimnya fasilitas baik saranaprasarana yang ada saat ini, menyebabkan belumseluruh wilayah yang ada di Kabupaten Bengkulu Selatan terlayani akses persampahan, dari 11 (sebelas) wilayah kecamatan yang ada, baru 3 kecamatan yang terlayani pengangkutan sampah oleh DLHK di Kabupaten Bengkulu Selatan. Sedangkan 8 (delapan) kecamatan lain belum terlayani karena keterbatasan fasilitas pengangkutan sampah yang dimiliki oleh DLHK, sehingga masih banyaknya sampah yang belum terangkut di Kabupaten Bengkulu Selatan.

Berdasarkan hasil wawancara dengan para informan mengenai terbatasnya SDM yang ahli di bidang persampahan, kurangnya fasilitas seperti kurangnya armada pengangkut sampah dan TPS dan kurangnya anggaran biaya, pihak DLHK telah berupaya untuk mengatasi masalah tersebut misalnya untuk meningkatkan SDM yang memiliki kemampuan dan keahlian di bidang persampahan, maka setiap staf/pegawai disana diberikan pelatihan sesuai dengan bidang masih-masih. Sedangkan untuk masalah kurangnya fasilitas baik itu armada pengangkut sampah, TPS, TPS $3 \mathrm{R}$ pihak DLHK terus berupaya untuk menambah fasilitas yang ada yaitu dengan cara merekomendasikan penambahan fasilitas yang ada kepada pemerintah daerah.

\section{Disposisi}

Berdasarakan hasil wawancara yang telah dilakukan, peneliti memeperoleh informasi bahwa sikap pelaksana berkaitan dengan tingkat kepatuhan para pelaksana dan petugas lapangan dalam implmentasi kebijakan pengelolaan sampah sudah cukup maksimal, walaupun masih ada juga aparatur dan petugas lapangan yang melaksanakan tupoksi di luar peraturan yang ada. Sedangkan kalau untuk insentif/reward diberikan bagi orang yang melakukan penguran- gan sampah serta pengolahan sampah, belum ada karena masih terkendala dengan anggaran biaya.

Disposisi atau sikap para pelaksana dalam implementasi suatu kebijakan sangat menentukan akan keberhasilan suatu kebijakan. George C. Edward III merujuk Disposisi yakni merupakan faktor penting dalam pelaksanaan suatu kebijakan publik, dimana jika pelaksanaan suatu kebijakan ingin efektif, maka parapelaksana kebijakan tidak cuma mengetahui apa yang akan dilakukan tetapimereka harus memiliki kemampuan untuk melaksanakannya.

Mengacu pada penelitian ini berdasarkan hasil penelitian menunjukkan bahwa sikap para pelaksana kebijakan pengelolaan sampah di Kabupaten Bengkulu Selatan sudah cukup maksimal, para pelaksana kebijakan sudah mematuhi aturan-aturan yang telah ditetapkan dan telah melaksanakan tupoksi sesuai dengan peraturan yang ada. walaupun, terkadang masih ada juga para pelaksana yang mengerjakan tupoksi di luar peraturan. Sedangkan untuk pemberian insentif/reward bagi setiap orang yang melakukan pengurangan dan/atau pengolahan sampah di Kabupaten Bengkulu Selatan belum terlaksana sesuai dengan ketentuan karena masih terbatasnya anggaran yang di punya, serta belum diterapkan sepenuhnya disentif bagi siapa saja yang melanggar terhadap larangan dan pelanggaran tertib penanganan sampah yang telah ditetapkan.

Berdasarakan hasil wawancara yang telah dilakukan mengenai masih adanya para pelaksana kebijakan yang tidak menjalankan tugas dan fungsi berdasarkan ketentuan yang ada. pihak DLHK telah memberikan teguran ataupun peringatan Menurut peneliti sendiri seperti teguran tertulis, berupa peringatan 1, peringatan 2 , peringatan 3 .

\section{Struktur Birokrasi}

Berdasarakan hasil wawancara yang telah dilakukan, peneliti memeperoleh informasi bahwa struktur organisasi DLHK telah terkoordinasi dengan baik dan telah adanya standar operating procedur (SOP) namun untuk pelaksanaannya belum sepenuhnya memenuhi standar operating prosedur (SOP). Sedangkan untuk pembagian tugas dalam pelaksanaan kebijakan perda tentang pengelolaan sampah di Kabupaten Bengkulu Selatan sudah jelas. 
J1AD: Jurnal Ilmu Administrasi dan Pemerintahan Indonesia Volume 02 No 02 December 2021 Pages 92-101

Struktur birokrasi dalam suatu kebijakan sangat diperlukan dalam keberhasilan suatu kebijakan. Dimana walaupun sumber daya untuk melaksanakan kebijakan sudah memadai, para pelaksana sudahmengetahui apa yang akan dilakukan, serta adanya keinginan para pelaksana dalam melakukan kebijakan, namun meskipun semua itu telah terpenuhi namun jika ada kelemahan dalam struktur birokrasi maka kemungkinan suatu kebijakan tidak akan terlaksana atau terealisasi.

\section{Faktor penghambat implementasiKebi- jakan pengelolaan sampah di kab. Beng- kulu Selatan}

Berdasarakan hasil wawancara yang telah dilakukan maka peneliti memperoleh informasi bahwa adapun yang menjadi faktor penghamabat dalam implementasi Kebijakanpengelolaan sampah di kabupatenBengkulu Selatan yaitu pertama, Komunikasi : kurangnya anggaran biaya untuk melakukan sosialisasi. Kedua Sumber daya : terbatasnya SDM yang ahli di bidang persampahan, kurangnya fasilitas baik, TPS, TPS $3 \mathrm{R}$ serta kurangnya armada pengangkut sampah dan masih terbatasnya anggaran dana oprasional dalam pengelolaan sampah. Ketiga, Disposisi : masih ada aparat yang melaksanakan tupoksi di luar peraturan yang ada. keempat, Struktur birokrasi : masih ada beberapa petugas/pelaksana yang menjalankan tupoksi tidakksesuai dengan SOP yang telahditetapkan.

Berdasarkan hasil penelitian mengungkapkan bahwa sejauh ini dalam Implementasi kebijakan pengelolaan sampah di Kabupaten Bengkulu Selatan DLHK sudah mempunyai standart Operating Prosedur (SOP) yang jelas baik itu mekanisme dalam pelaksanaannya, sistem dan prosedur dalam pelaksanaannya, serta tupoksi dan tanggung jawab yang telah diberikan oleh para pelaksana terkait kebijakan pengelolaan sampah.Namun untuk pelaksanaan di lapangan Berdasarkan hasil wawancara dan observasi yang telah dilakukan peneliti menemukan walaupun dalam pelaksanaan kebijakan sudah mempunyai Standar Operating Procedure (SOP) namun pada kenyataannya di lapangan masih ada para pelaksana/petugas yang belum sepenuhnya memenuhi standar operating prosedur (SOP) yang telah ditetapkan. Sedangkan untuk penyebaran tanggung jawab kepada pelaksana kebijakan da- lam pelaksanaan kebijakan pengelolaan sampah di Kabupaten Bengkulu Selatan telah disebarkan secara jelas dan sudah terstruktur dalam strukturorganisasi pelaksana sesuai dengan petunjuk teknis kebijakan yang dikeluarkan Bupati, dan struktur organisasi DLHK telah terkoordinasi dengan baik.

Berdasarkan hasil penelitian yang telah dilakukan mengenai masih ada para pelaksana yang menjalankan menjalankan tugas dan fungsi nya sesuai dengan Standar Operating Prosedur (SOP) yang telah ditetapkan. Pihak DLHK telah berupaya untuk mengatasi masalah tersebut seperti berdasarkan hasil wawancara yang telah dilakukan pihak DLHK selalu memberikan arahan dan instruksi agar para pelaksanaan dalam penyelenggaraan kebijakan pengelolaan sampah di Kabupaten Bengkulu Selatan mengikuti SOP yang telah ditetapkan.

\section{SIMPULAN}

Berdasarkan hasil dan pembahasan mengenai Implementasi Kebijakan Pengelolaan Sampah di Kabupaten Bengkulu Selatan maka peneliti dapat menarik kesimpulan sebagai berikut:

1.Implementasi Kebijakan Pengelolaan Sampah di Kabupaten Bengkulu Selatan sudah berjalan sesuai standar dan prosedur yang telah ditetapkan namun dalam pelaksanaannya belum sepenuhnya terealisasi sesuai dengan isi kebijakan, serta masih ada ketidaksesuaian yang didapat dari hasil pelaksanaan kebijakan karena masih mengalami beberapa hambatan dalam pelaksanaannya.

2. Adapun faktor penghambat dari implementasi kebijakan pengelolaan sampah di Kabupaten Bengkulu Selatan adalah : Pertama, Komunikasi : kurangnya anggaran biaya untuk melakukan sosialisasi. Kedua, Sumber daya : terbatasnya SDM yang ahli di bidang persampahan, kurangnya fasilitas baik, TPS, TPS ${ }_{3} \mathrm{R}$ serta kurangnya armada pengangkut sampah dan masih terbatasnya anggaran dana oprasional dalam pengelolaan sampah. Ketiga, Disposisi : masih ada aparat yang melaksanakan tupoksi di luar peraturan yang ada. Keempat, Struktur birokrasi: masih ada beberapa petugas/pelaksana yang menjalankan tupoksi tidak sesuai dengan SOP yang telah ditetapkan. 


\section{DAFTAR PUSTAKA}

Alwi, \& Kasmad, R. (2018). Local collaborative network: Is it smart implementer of the cocoa business development policy in Indonesia? International Journal of Public Policy, 14(5-6). https://doi.org/10.1504/ ijpp.2018.10017926

César, M., Kumpulainen, K., Oramas, C. V., Aarons, G. A., Fettes, D. L., Sommerfeld, D. H., ... Eversole, R. (2017). Accomplishment Index Analysis of the Sociophysical Activities of Community-Based Organizations in a Postconflict Area of Africa. Journal of Public Policy, 6o(1), 1-25. https://doi.org/10.1017/ s0143814x10000206

Danang Aji Kurniawan, D. A. K., \& Ahmad Zaenal Santoso, A. Z. S. (2021). Pengelolaan Sampah di daerah Sepatan Kabupaten Tangerang. ADI Pengabdian Kepada Masyarakat, 1(1), 31-36.https://doi.org/10.34306/ adimas.v1i1.247

Fernando, R. L. S. (2019). Solid waste management of local governments in the Western Province of Sri Lanka: An implementation analysis. Waste Management, 84, 194-203. https://doi.org/10.1016/j. wasman.2018.11.030

Fitri, R. F., Ati, N. U., \& Suyeno. (2019). Implementasi Kebijakan Pemerintah dalam Inovasi Pengelolaan Sampah Terpadu. Jurnal Respon Publik, 13(4), 1218. Retrieved from http://riset.unisma.ac.id/index. $\mathrm{php} / \mathrm{rpp} /$ article/view/3577

Lu, H., \& Sidortsov, R. (2019). Sorting out a problem: A co-production approach to household waste management in Shanghai, China. Waste Management, 95, 271-277. https://doi.org/10.1016/j.wasman.2019.06.020

Mengoptimalisasi, D., \& Sampah, B. (2021). Implementasi Kebijakan Pemerintah Kota Bitung Dalam Pengelolaan Sampah Dengan Mengoptimalisasi Bank Sampah. Jurnal Politico, 10(4), 1-10.

Robert K.Yin. (n.d.). Case Study Research_Design and
Methods, Third Edition, Applied Social Research Methods Series, Vol 5 (2002).pdf.

Rulinawaty Kasmad, Samboteng, L., \& Mahsyar, A. (2019). The Unwise Policy Of Community Based-Organisation: Can It Empower Them? Implementation Network Of Food Diversification In Indonesia Rulinawaty. OPCION, 35(22), 2900-2961. https://doi. org/10.1017/CBO9781107415324.004

Sabatier, P., \& Mazmania, D. (1980). Sabatier_et_al1980-Policy_Studies_Journal. Retrieved from https://s3.amazonaws.com/academia.edu.documents/33366842/Implementation.pdf?AWSAcce ssKeyId=AKIAIWOWYYGZ2Y53UL3A\&Expires =1539806052\&Signature $=$ oM8Z7rAKnCJbmLcCwu HUnlN9CxM\%3D\&response-content-disposition= inline\%3B filename\%3DCONCEPTUAL_FRAMEWORK_THE_IMPLEMEN

Sharma, M., Joshi, S., Kannan, D., Govindan, K., Singh, R., \& Purohit, H. C. (2020). Internet of Things (IoT) adoption barriers of smart cities' waste management: An Indian context. Journal of Cleaner Production, 270, 122047. https://doi.org/10.1016/j. jclepro.2020.122047

Van Meter, D. S., \& Van Horn, C. E. (1975). The Policy Implementation Process: A Conceptual Framework. Administration \& Society, 6(4), 445-488. https:// doi.org/10.1177/009539977500600404

Wichai-utcha, N., \& Chavalparit, O. (2019). 3 Rs Policy and plastic waste management in Thailand. Journal of Material Cycles and Waste Management, 21(1), 10-22. https://doi.org/10.1007/s10163-018-0781-y

Yin, Rk, K. (2013). Case study research: Design and methods (4th Ed.). Thousand Oaks, CA: Sage. The $\mathrm{Ca}$ nadian Journal of Action Research, 14(1), 69-71. https://doi.org/10.33524/cjar.v14i1.73

Zorpas, A. A. (2020). Strategy development in the framework of waste management. Science of the Total Environment, 716, 137088. https://doi.org/10.1016/j. scitotenv.2020.137088 